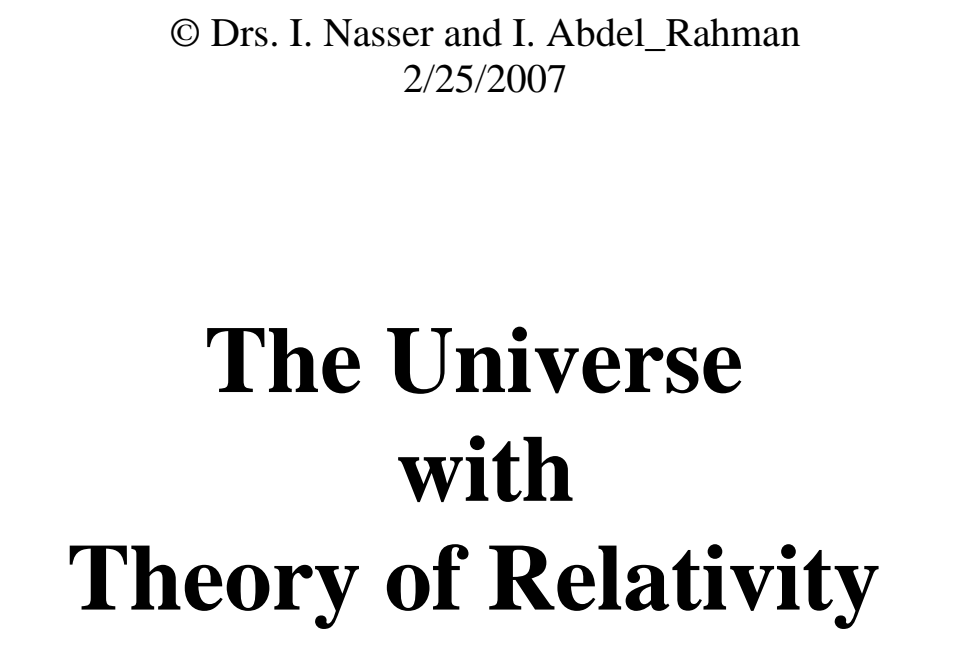

تجمبع

\begin{tabular}{|c|c|}
\hline 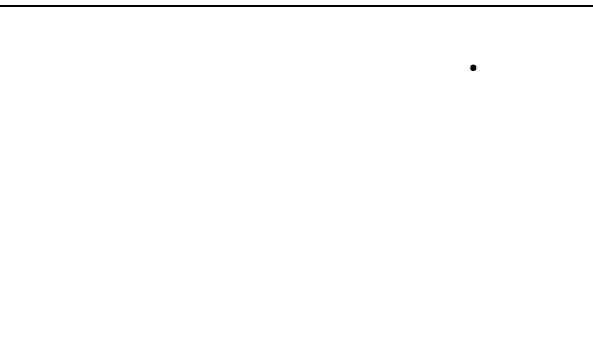 & 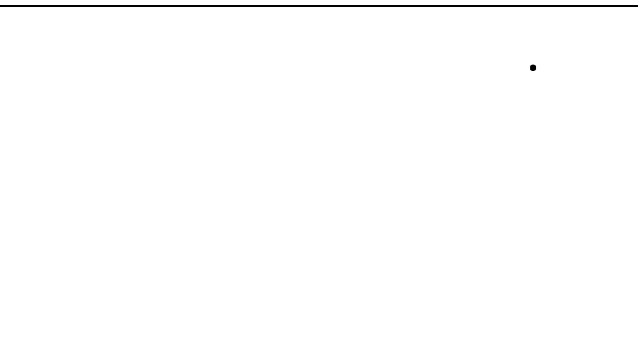 \\
\hline
\end{tabular}


(C) Drs. I. Nasser and I. Abdel_Rahman

$2 / 25 / 2007$

\section{ظالرة تاريخية}

\section{"Historical View"}

في هذا البلبسف نسنعرض أهم المشلك الت واجهت عالماء الفيزباء والفك والت أمت إللظهور ظربلت جنية مل ميكانيكا الكم والظارية النسبية.

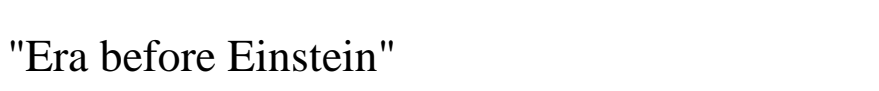

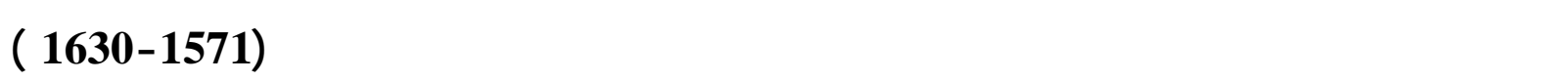
الني دسسسلوك الكولك وتمكن منشرح حركنها ولستنبلا الثلاثةقولنين السبلسية في حركنها وهم:

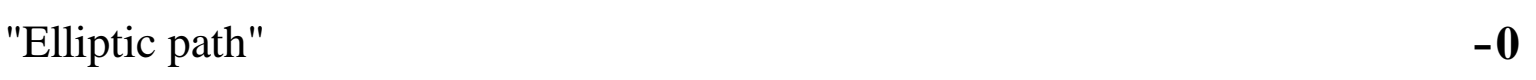
وتكهن اللثس إحعى بؤرتي المسار.

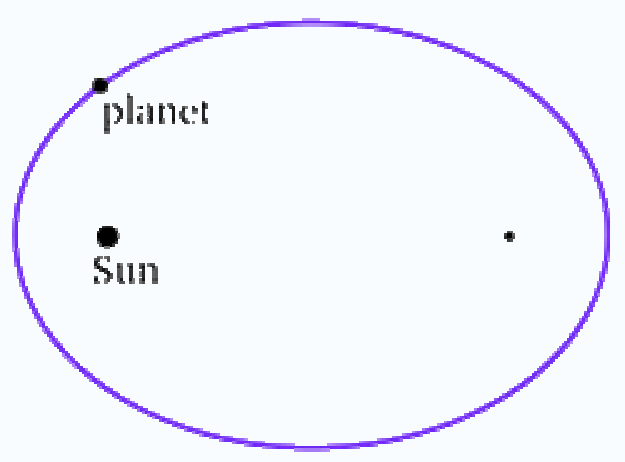

0 - الظا الوالطل بين الكوكب واللثهس يمسح مساحلتمنساوبة في لأزمنة المتساوبة. ومعبارة أخرى تزرداسرعة الكوكب كاماكلن قريباً من اللشعس.

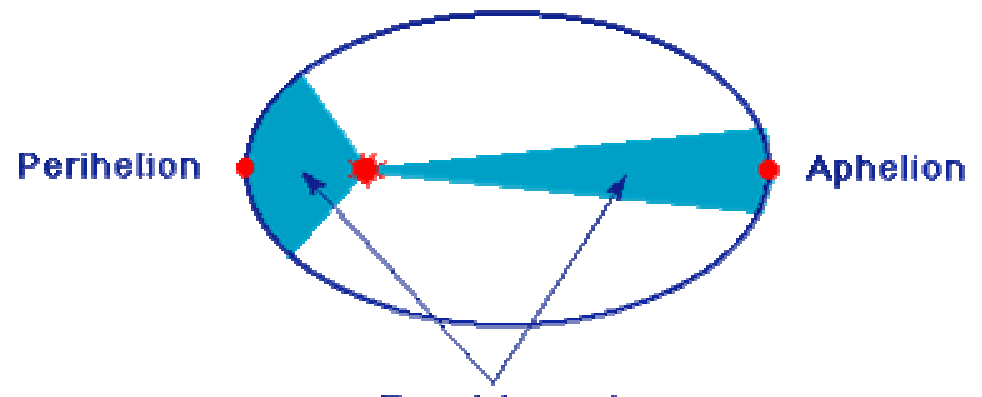

Equal Areas in

Equal Times

2 - الكوكب الأفرب إلل اللثس يكون زمن دورلنه حط اللثس أللمن الأبد عن اللثس. 
(C) Drs. I. Nasser and I. Abdel_Rahman

$2 / 25 / 2007$

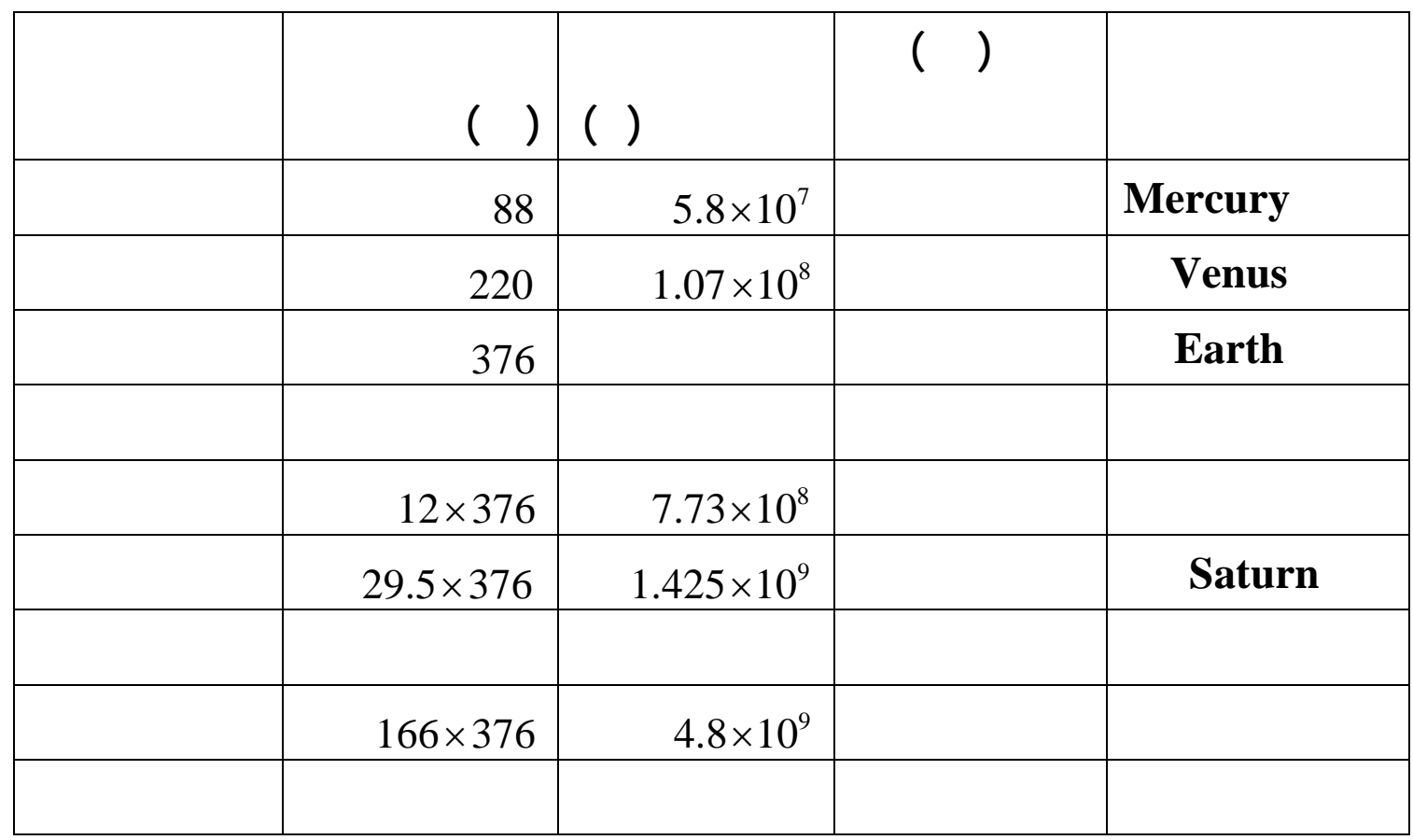

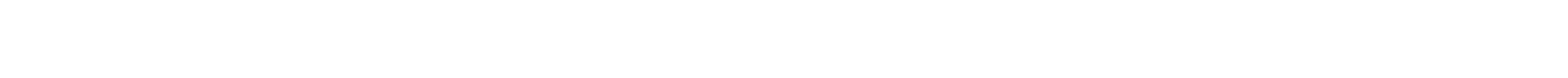
أن:

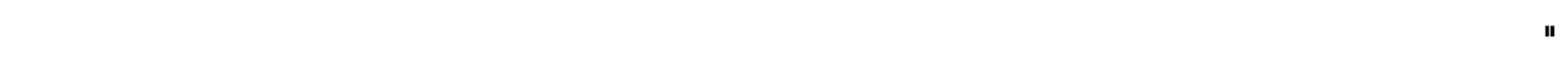
وعكسياًمع مريع المسلفة بينهما" ورياضيا يعبر عنه بالفلنون:

$\longleftrightarrow$ r
\[ m_{1} \bullet F_{12} \quad F_{21} \leftarrow \bullet m_{2} \]
$F_{12}=F_{21}=G \frac{m_{1} m_{2}}{r^{2}}, \quad G$ is the gravitational constant

وقد الستخم نيون النظا اللانيف Gravita (ومعنه الظل أو الوزن) وهو اللسب في تسميته بقلنون الجانبية اللهلم. هذا بالإضلكة لفولنين نيون الثلاثة وهه: 
3 - يستمر الجسم عل حالته من السكهن أو الحركة في خط مسقم إلا إذا أثرت عليه قوة خارجية. 4 - إذا أثرت قوة عل جسم فإلن النسارع الناتج يتنلبعطرياً مع الفوة المؤثرة وتننلب عكسياً

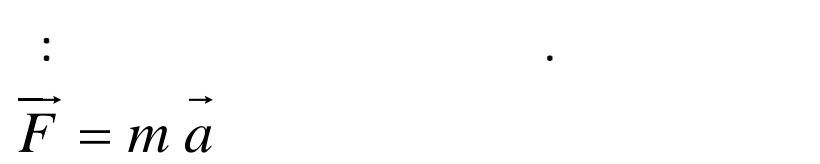

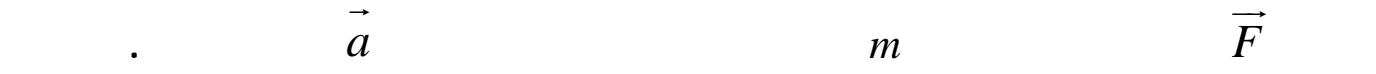

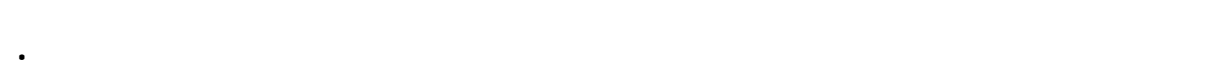
5 - لل فلل ردفلى مساو له في الفقدار ومضاد له في الانجاه. وقد اعتبر نيوتن في قولنينه أن المكلن والزملن كميلت سلفة. والترة ليست بالفصيرة، وظاراً لهصورف الإكلنيلت المعملية، وحت نهلية الفرن التلسع عشر، كلت جمبع قولنين الفيزباءمبنية على ألسطس: ت -قولنين نيوتن ف الميكليكا وقانهن الجانبية. ث - معادلات ماكسول لومف الكهربية والمغنليسية. ج -الميكانيكا الإحصائية لومف حالة النجمعات الكبيرةمن المالة.

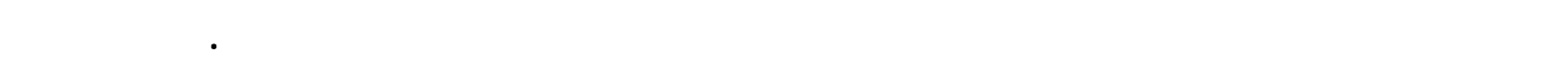

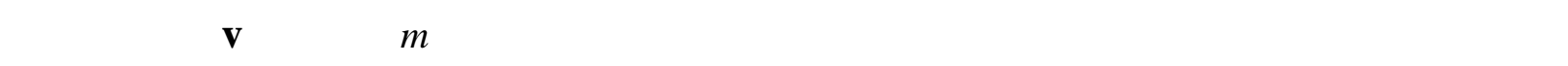
خلية (Distinguishable)

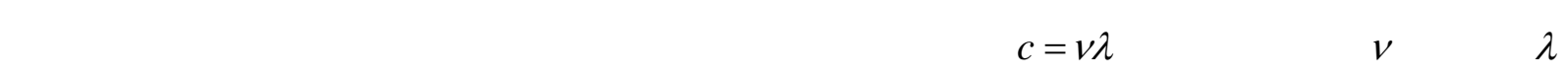

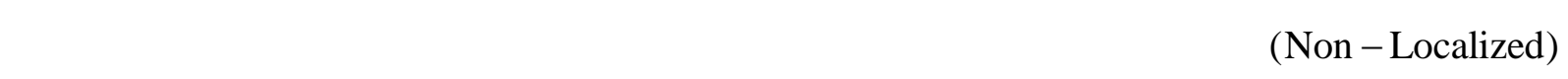

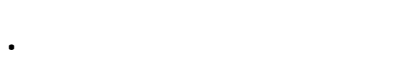
وسنهلية الفرن التلسع عشر ودالية القرن الهشرن وظلراً للملورفي الإمكلنيل المعملية فقدظهرت أشياء كثيرةظلت بذهن فسير بولمطة قولنين الفيزباء القلينية. وعندا لكتثف الإلكترهن كبنية أسلسية ف الذرة (نموذج راذرفورد)، ألسبح التركيب الذري غنيا بالمعلوملت ولكنها غالمضة ومبهمة.

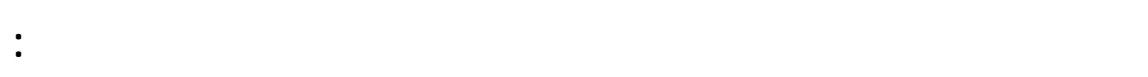


(C) Drs. I. Nasser and I. Abdel_Rahman

2/25/2007

3 - إثماعاع البعم الأسود (Black body radiation) 4 - اللاهرة الكهوضوئية (Photoelectric phenomena) 5-مبادئ الظلربة الذربة (Principle of atomic theory)

6 - 6 - تشت كمتهن (Compton scattering) 7 - حيود جمع ألنواع الجسيمك (Diffraction of particles)

8 - تجرية ميكلسهن تمورلي * (Michelson-Morely experiment) 9 - دورلنمستوى مداركوكب علارد (Orbit precession of Mercury)

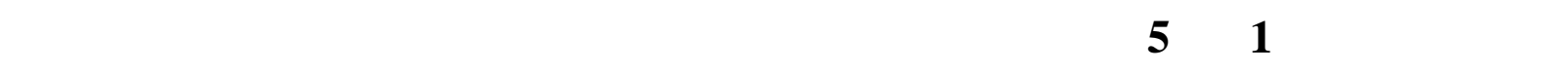

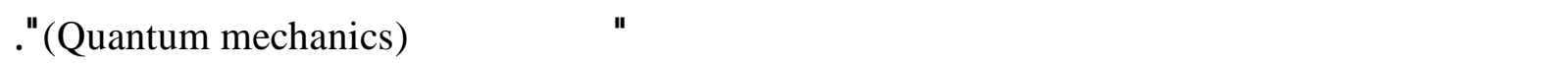
وقد بدأ هذا العلم عنداظاهر فرض ماكس بلاكل بخصوص تكمم اللالفة الكهومغنلاليسية المظالفة

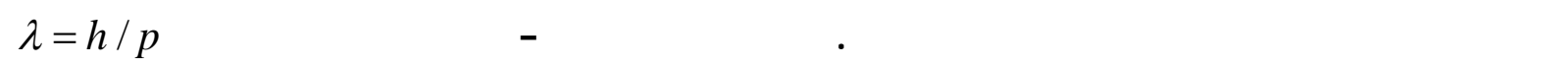
اللهسيمات حيث هوكمية الحركة الظية للجسيم. الصعومة رقم 6 ألت إليفهور الظاربة النسبة لأينشتن والثي توائت مع قولنين ملكسول ولن

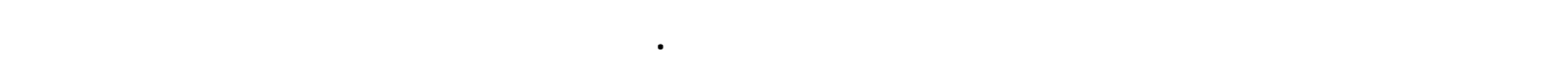

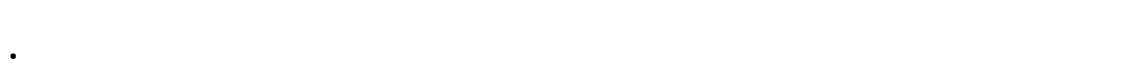

* تجرية مايكلسهن تمورل وضمت للتبقق من فرضية أنسرعة الضوء الفقلسة بلتجاه حركة دورل الأرض تكهن لكبر منسرعة الضوء الني يسير بالجاه معاكس لحركة دورل الأرض. ولهن وجد أن

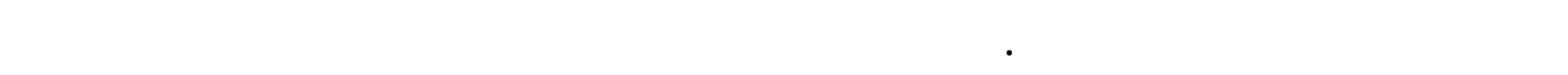

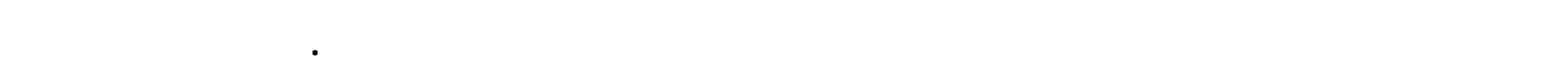

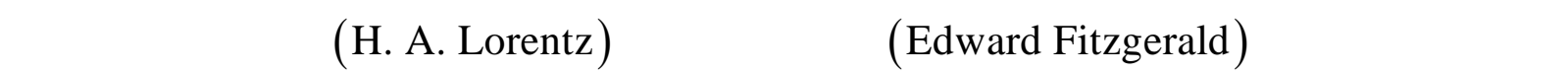
عنطرق إثبلت أن لُٔلول الأبسلم تقاص في الجاه حركنها. 


\section{البلب الألط القالرية النسبية}

"Theory of relativity "

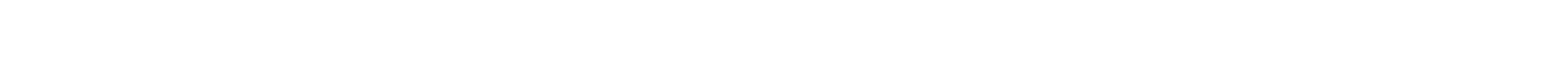
ألا وهما التاربة النسبية الخاصة والقالربة النسبية العامة.

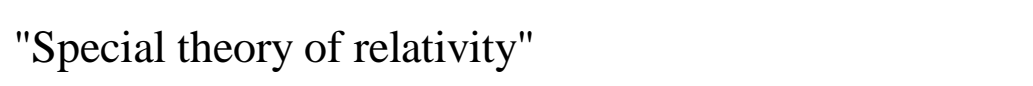
وضمها لينشتلين في علم 1905ه، وه تدطس حركة الأبسلم المتحركة بسرعة منتلمة في خط مسقفم (ألالرموضمي). وقد بنيت الظالربة على الفرضين التالين: 1 - سسرعة الضوء في الفراغ لها فه الفيمة ف جمع المجموعلت الإحداثية المتحركة بالنسبة لبهضها بسرعة منتّلمة (لإلارات مرجعية لبهضها البهض) 2 - القولنين اللبيعية واحة في جمع المجموعلت الإحداثية المتحركة بسرعة منتلمة بالنسبة لب: ملحظلة: هذه الظاربة لم يسظلع لٓيثشتلن قلبقها عل حركة الكولب والنجوه، حيث أنها تنحرك بتسارع في مسارك دائربة أوبيضاوبة.

\section{وقد النبق من هنه الظاربة اللولهر التالية:}

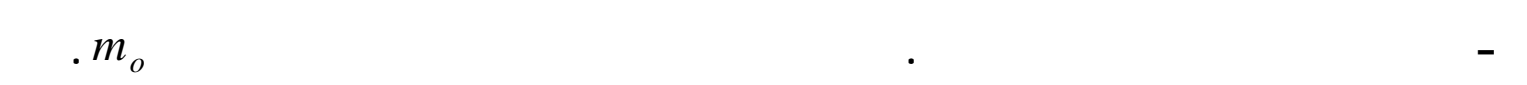

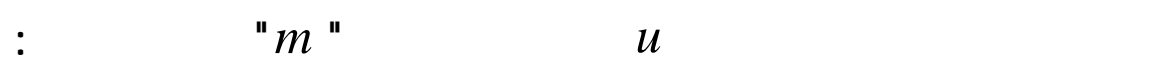

$$
m=\frac{m_{o}}{\sqrt{1-\left(\frac{u}{c}\right)^{2}}}
$$

حيث c هيسرعة الضوءفي الفراغ. نلاظل هنا أن كتلة الجم تززدادمع زبادة السرعة. 


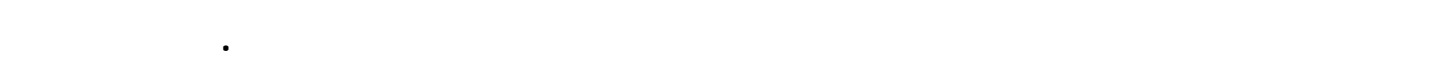

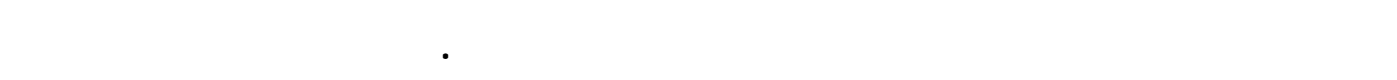

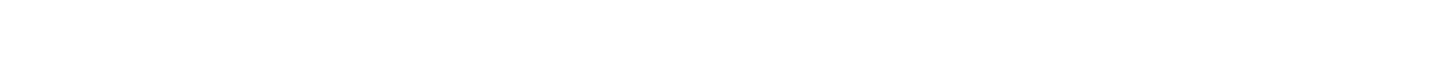
للسرعة. ب - قِصرطط الجسم في الجاه حركته (Length contraction) . يعرفطل جسم متحرك بأنه

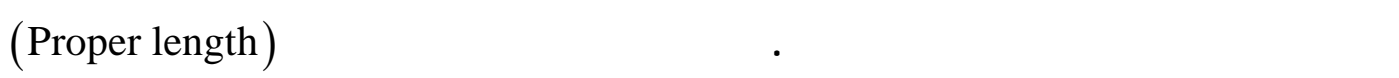

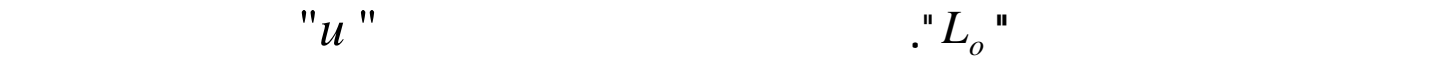

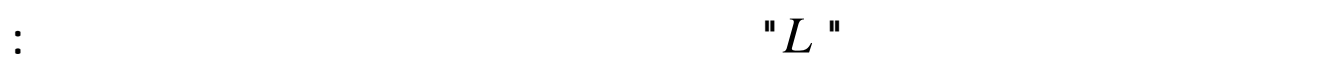

$$
L=L_{o} \sqrt{1-\left(\frac{u}{c}\right)^{2}}
$$

حيث c هيسرعة الضوءفي الهراغ. نلاطظ هنا أنطلط الجسم المتحرك، والمقلسه بولمطة ملاط خارجي، يقاه مع زبالة اللسرعة في التجاه حركته فتا، وليس في أي الجهاه لخر.

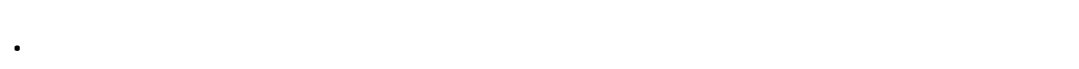

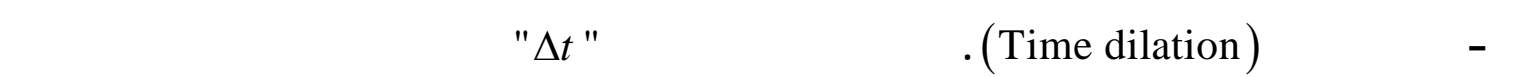

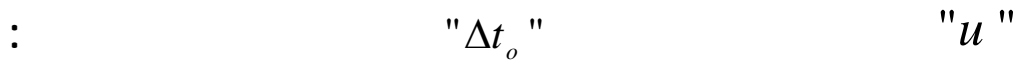

$$
\Delta t=\frac{\Delta t_{o}}{\sqrt{1-\left(\frac{u}{c}\right)^{2}}}
$$

ولهذا نجد أن فرق الزمن المقلسف لإلارمتحرك ياهر به بهض من التأخير عنفرق الزمن

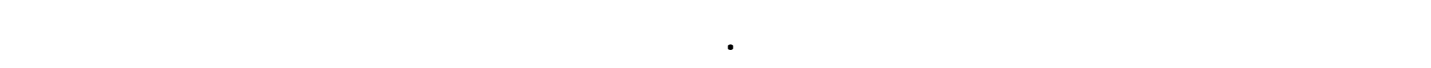

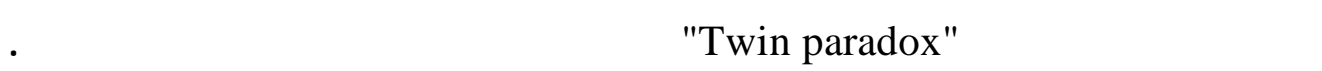

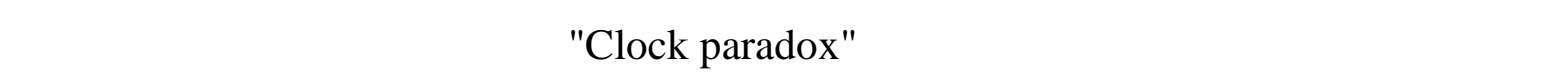
التي النبقت عن الظاربة النسبة الخامة.في هذه المسألة يلهر الفرق بين عمري توأمبن أحهذا

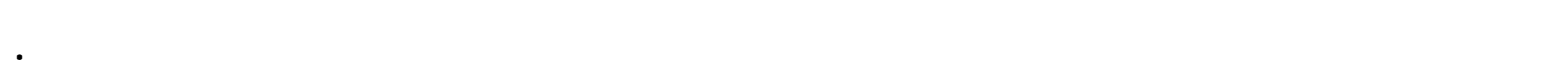

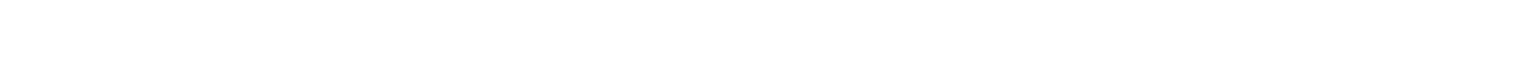

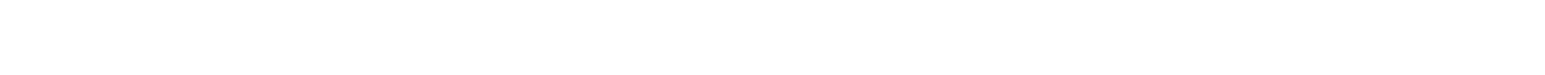
اللثقين التوأمبن عند القائهما على شملح الأرض يتونف على سسرعة اللفينة في الفضاء

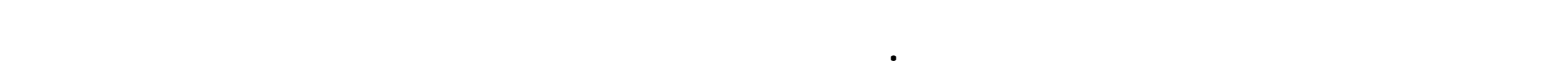




\section{(C) Drs. I. Nasser and I. Abdel_Rahman}

$2 / 25 / 2007$

هو الني ينحرك بالنبة للأخ المسلر، ومالتالي فهو يعتبر الأصغر عمرا. وقد الحلت عثة هنه الفارقة في النسبية العامة.

ث - تكالفؤ الكتلة ولالالة الني بعبر عنه بمعادلة الالفة المشهورة التالية:

$$
E=m c^{2}
$$

حيث (E) هي الالفة، (m) الكتالة، (c) عسرعة الضوء في الفراغ. وبتضح من المعادلة أن

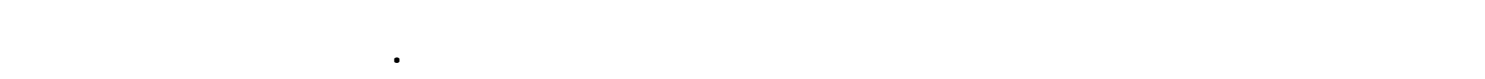
هائلة من الالفة تتولد من تحول كمية ضئيلة من المالة، وذك نتيجة لمرعسرعة الضوء بالة

والفقارنة بما يحمث في الشسب، نجد أنه تنولدكميت هائلة من الالفة بسبب عمليت الندماج النووي

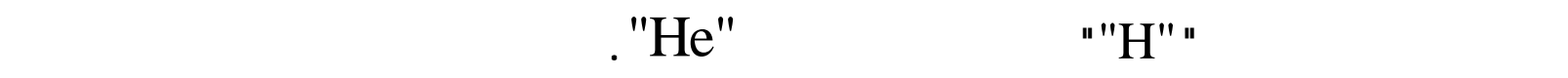

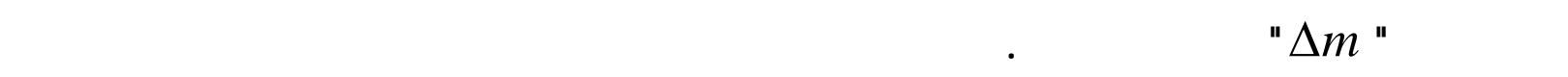

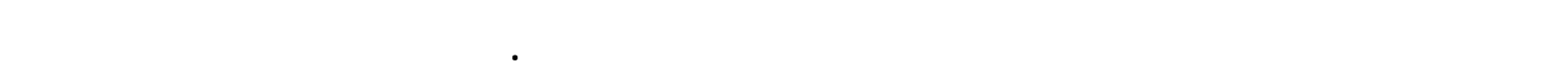

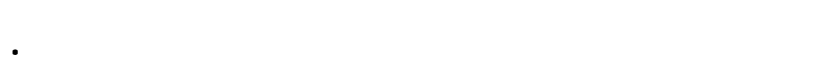


"General theory of relativity" القالربة النسبية الهامة

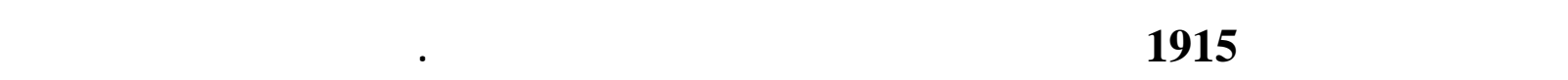
ملرجقتين مختلفتين، لأول: تستخم فيها قوة خارجية مؤثرة. وكمثل عل ذك أله عندما تبدأ بقياة عربك وتزبد من

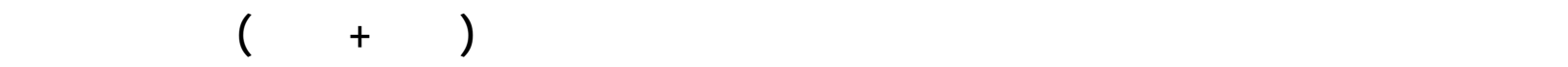

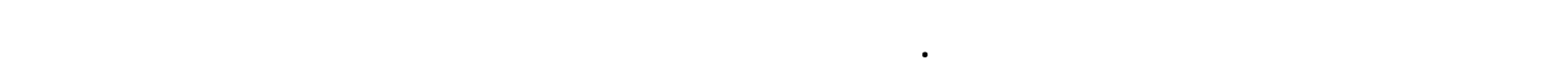

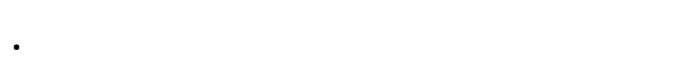

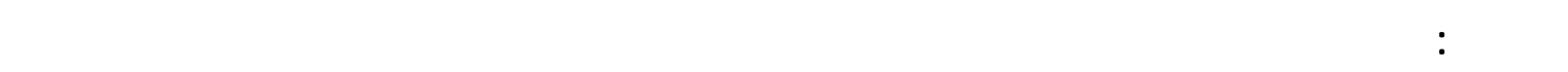

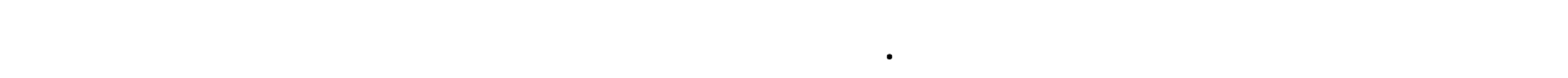

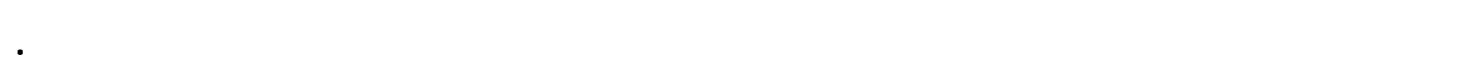

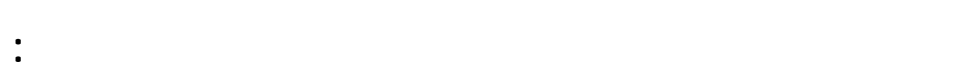

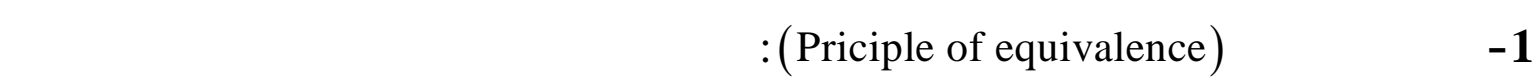

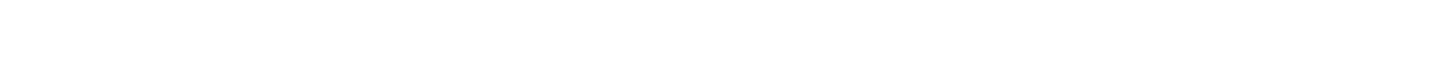

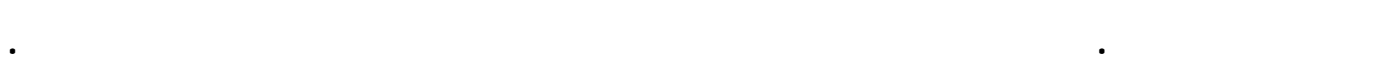

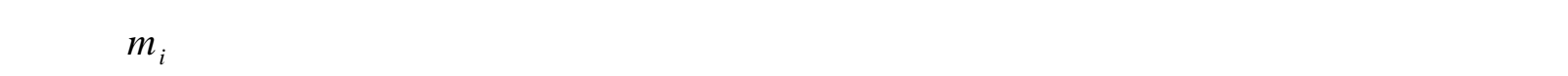
تهت تأثيرقوة خارجية

$$
\vec{F}=m_{i} \vec{a}
$$

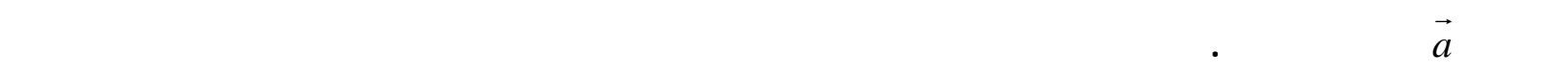

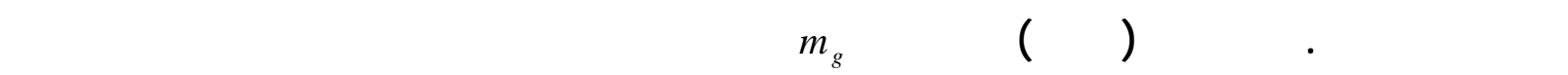
الجانبي، وتنأنق الجن المعادلة:

$$
\begin{aligned}
& \vec{F}_{g}=m_{g} \vec{g} \\
& \text { وقلبق مبدأ التكافؤ للكتلتين نجد أن: } \\
& m_{i} \frac{d^{2} x}{d t^{2}}=m_{g} g \\
& \frac{d^{2} x}{d t^{2}}=g
\end{aligned}
$$




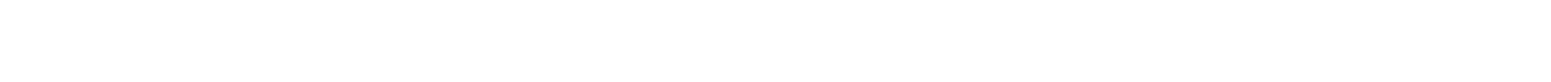

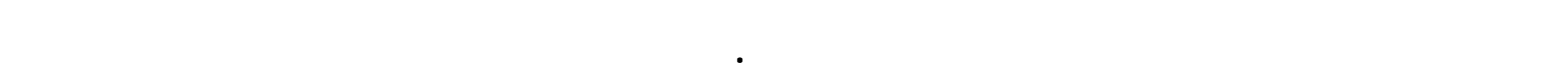
الثالن عشر. ومن الشرح السلق لفترح لينشتلين فرضه بنسبية الزملن والمكل (الزمكلن)، وهما من الأشياء

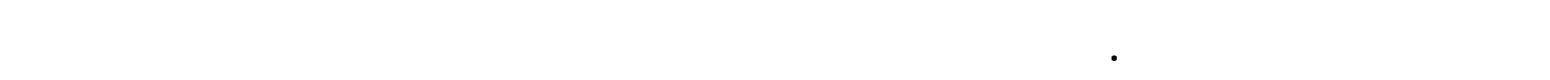

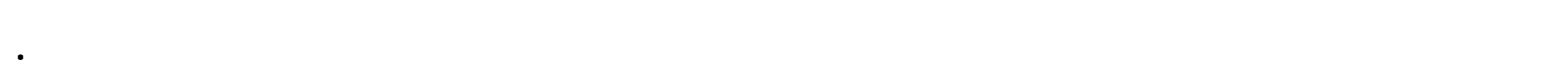

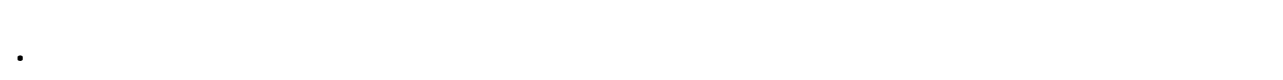
ويمكن وضع هذا المبدأ بصسغ مختلفة ومنها:

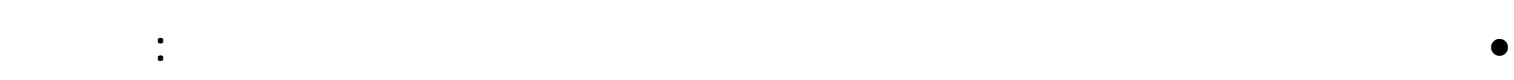

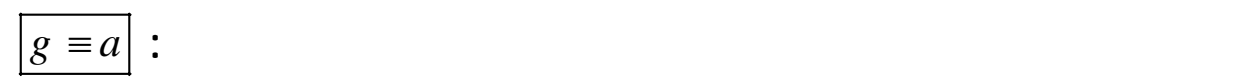

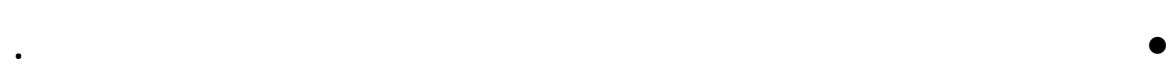

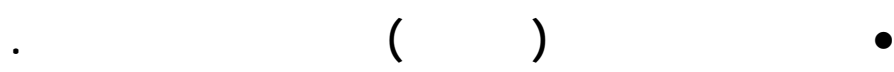
• أن الإلار المتسارع يكلئ الإلار التثلفلي.

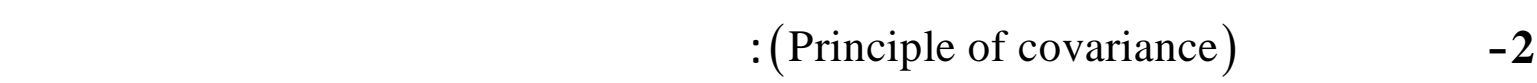
بتغير نوع الإحداثيلت الزمنية والمكلنية المستخدة.

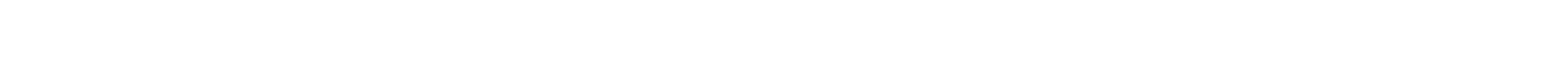

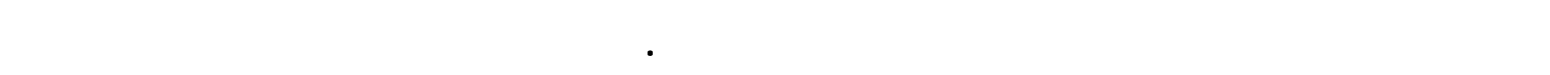

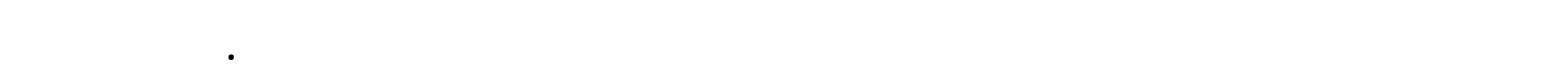

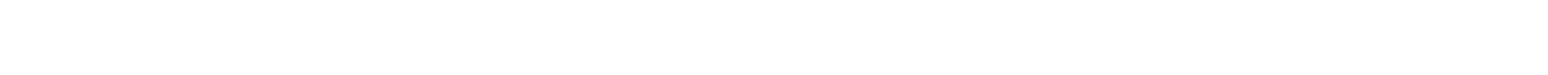
خاصة، زمنية أومكلنية.

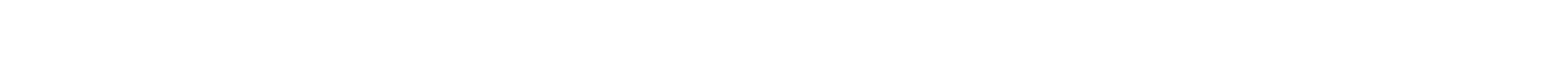

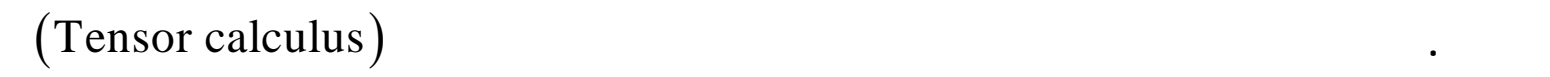

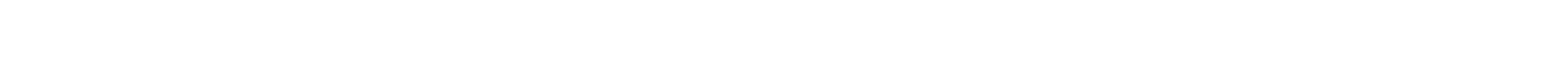
الإحدالثيت الأخرى. 


\section{(Curvature of space) (النحناء الفراغ (المكلن)}

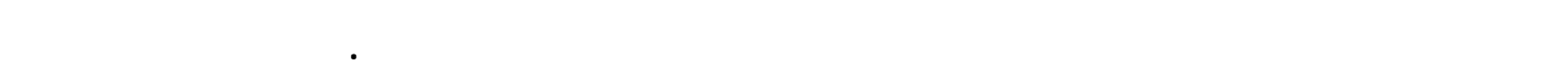

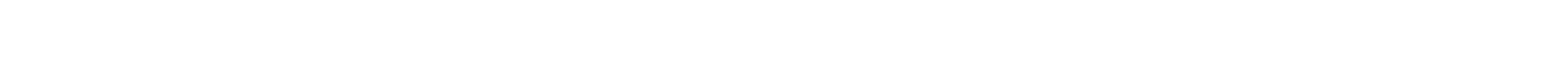

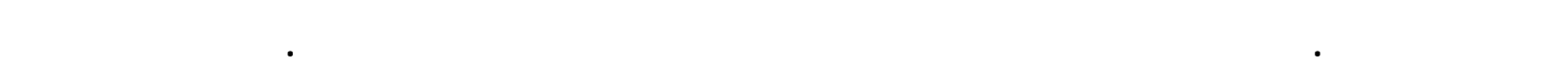

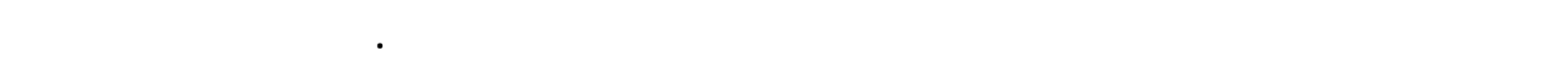

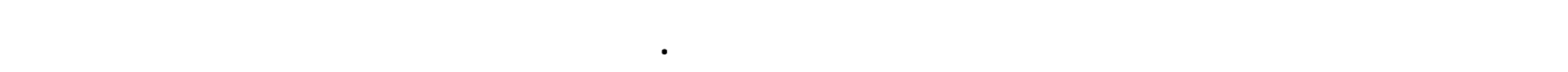

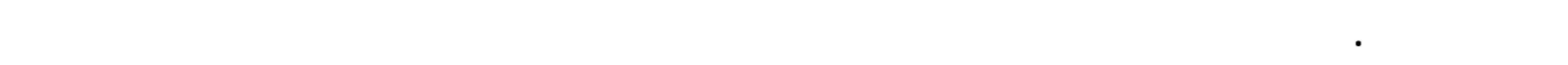
يظهر اللملح المعرون باللثل التلالي.

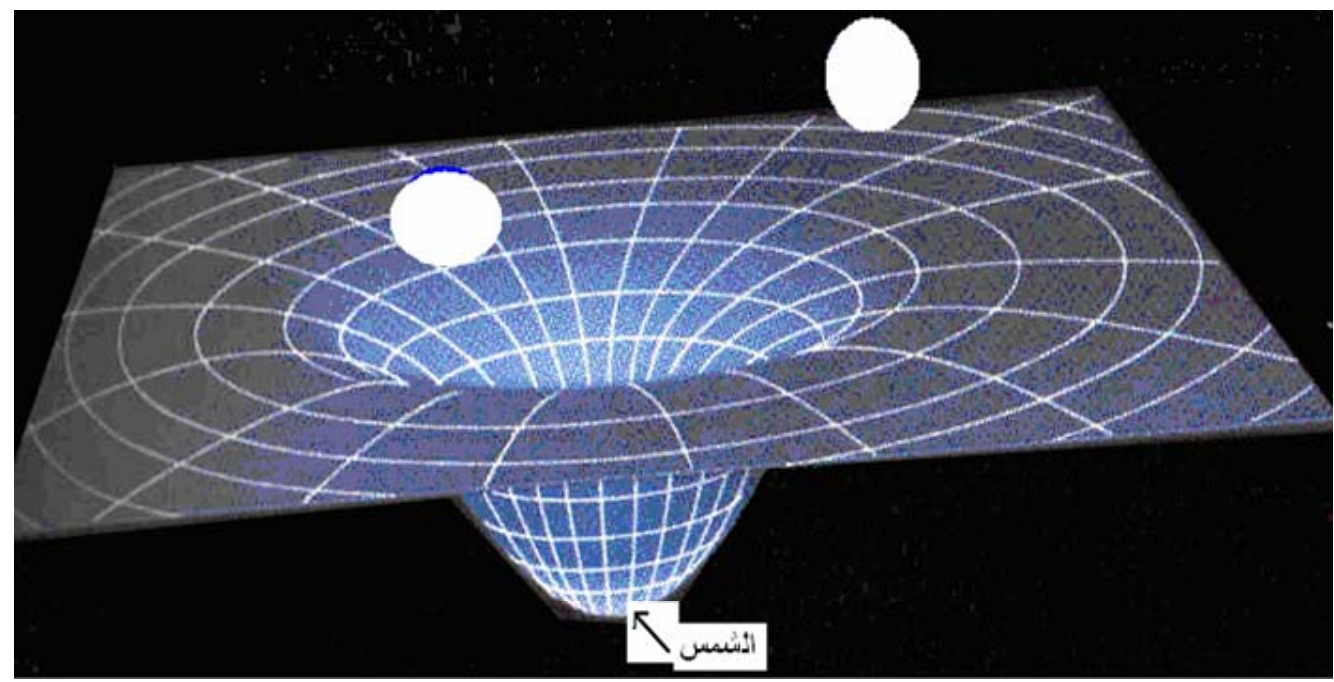

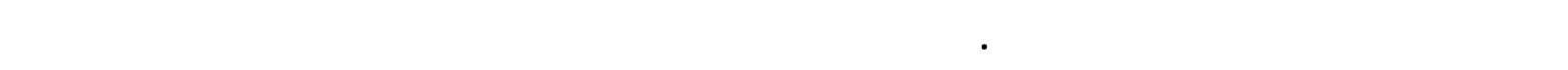

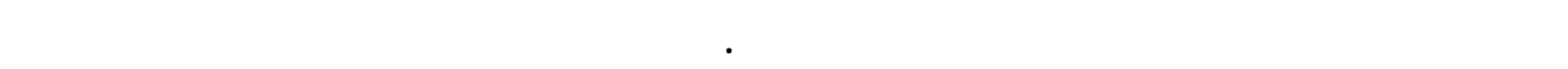

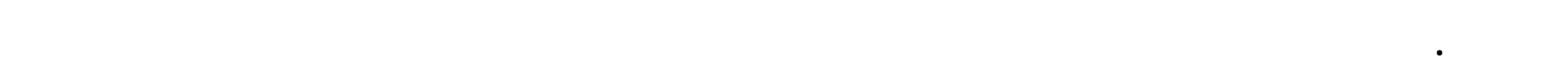

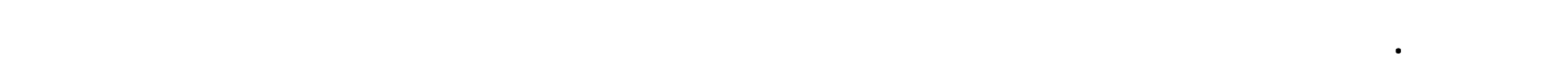

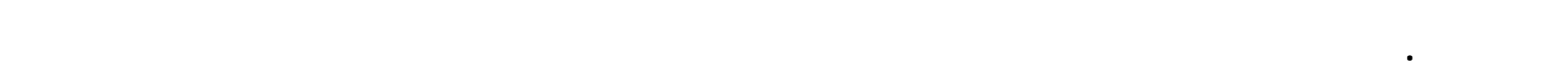
الجانبية المنساوي عل الأبسلم المخنافة. والخلاصة هنا: "أل وجود المالة يؤي إلل الحناء الزمكلن، ولنحناء الزمكل ، وسرعة الجسم، يمل عل البسم كفية

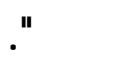


دورلنستوى مداركوكب علارد (Orbit precession of Mercury) كوكب علارد هو كرب كولب المجموعة اللثهسية إلل المسس، الذك فلن تألثره بجانبيتها يكهن كبيراً.

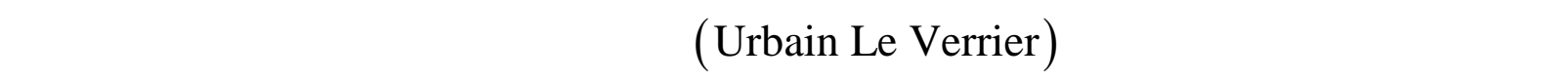

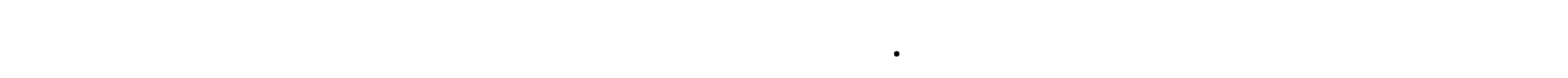

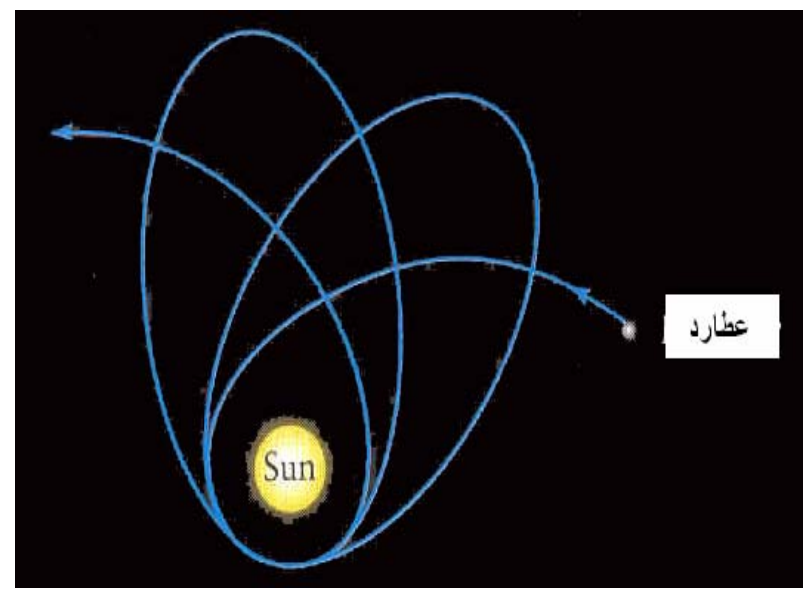

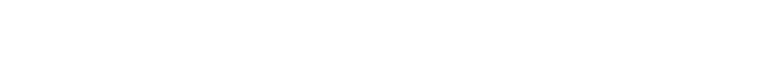
هو ملاظ باللثل المقلل، بزالوبة مقدارها

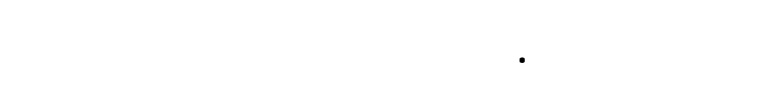
ملاينسنة لكي يقم مستوي المسار دورة كاملة.

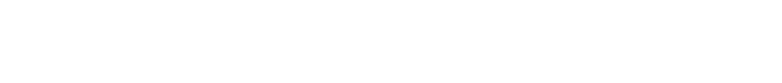

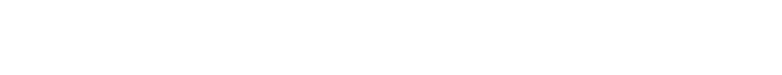
عل حركة المسار للكوكب.

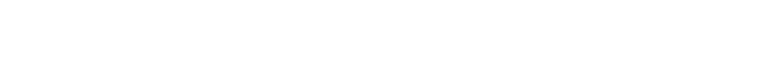

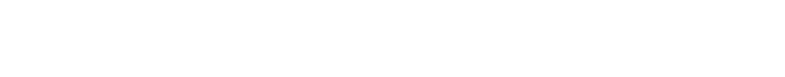

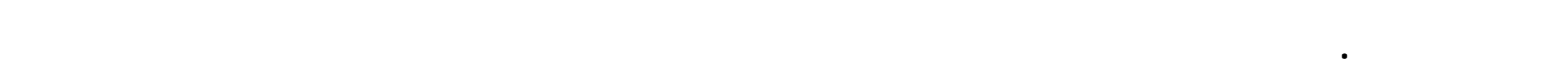

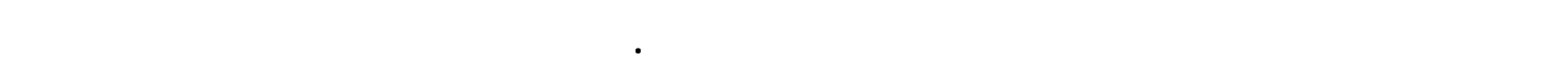

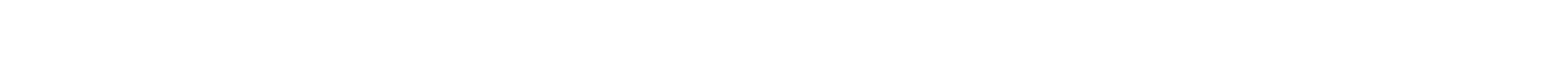

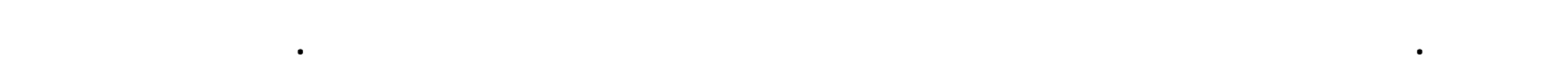

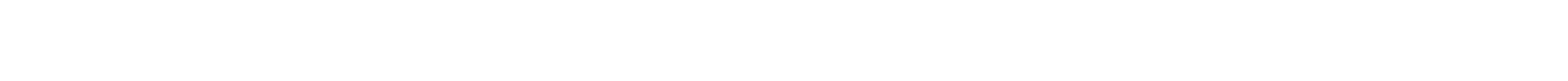

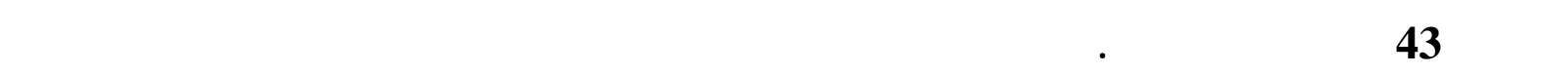
تؤككدهة ظاربة النسبية اللمهة.

\section{النفاء الضوء (Deflection of light)}

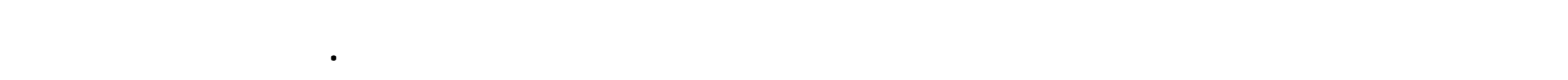

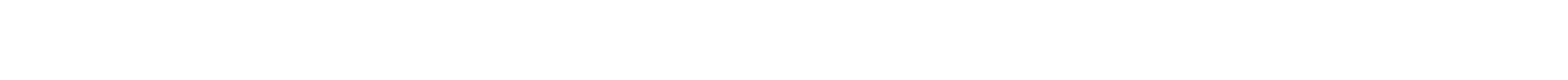

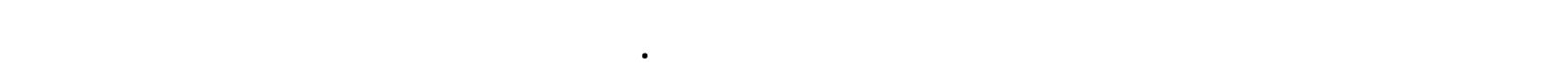

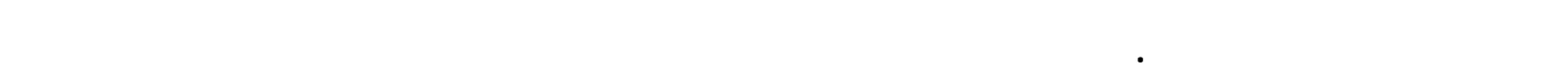
عنم الكتلة. 


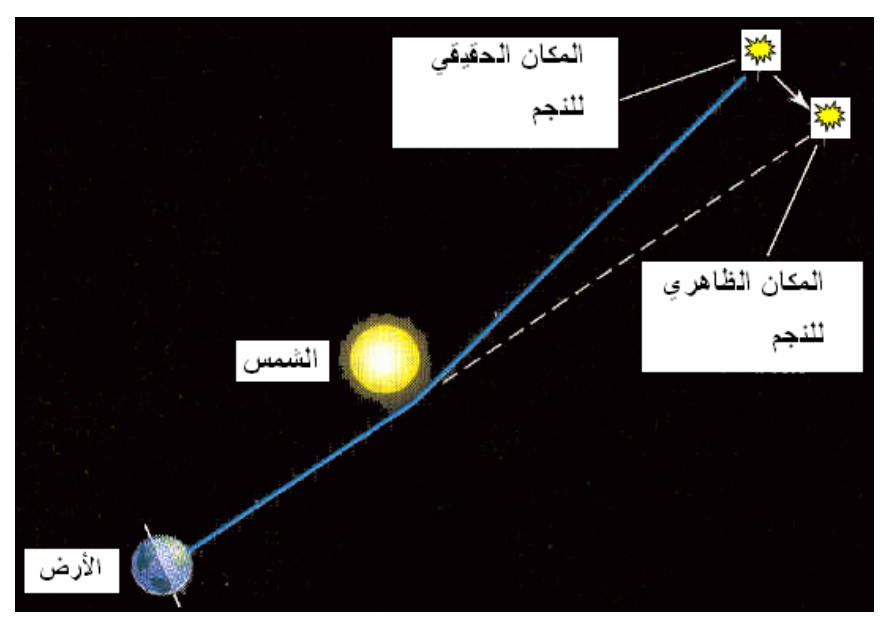

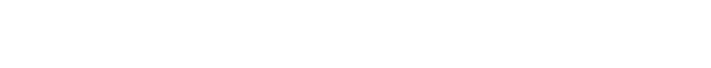

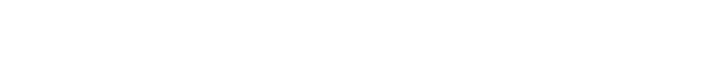

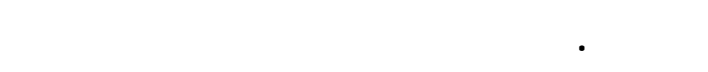

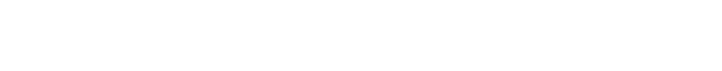

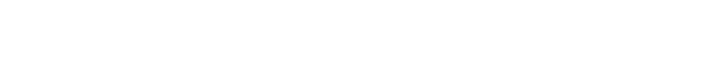

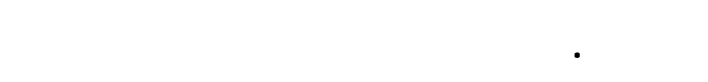

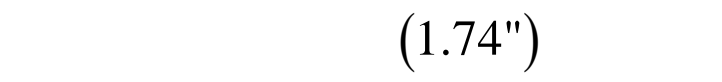
اللماعسمطح اللثعس.

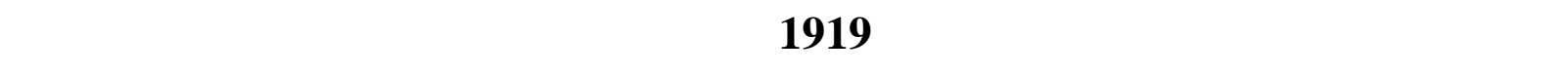

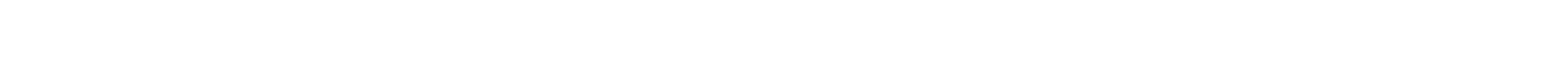

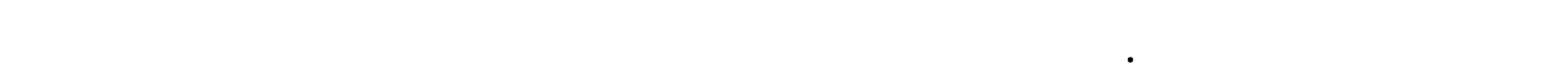
بقدار يفق مع ما توقوته ظارية آلينشتلن.

إزالحة الجانبية الحمراء (Gravitational red shift)

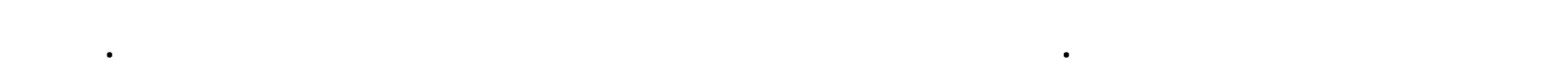

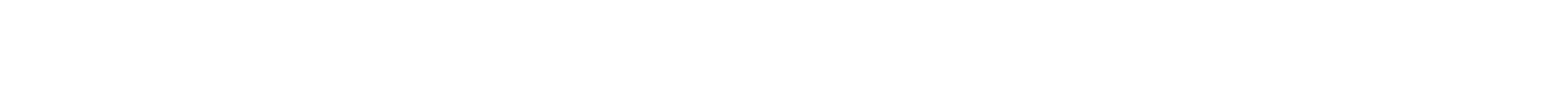

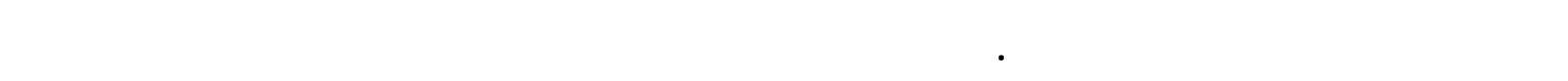

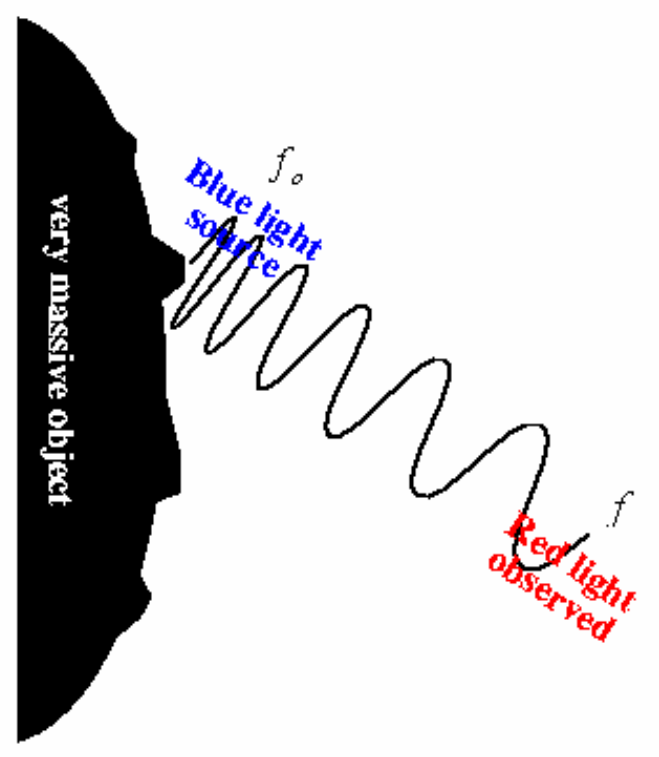

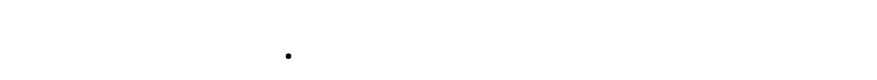

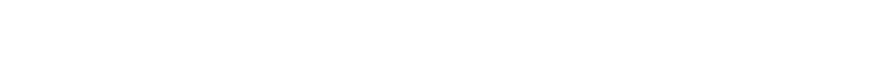

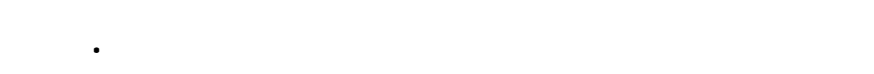

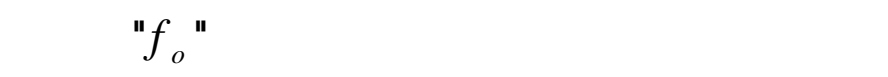

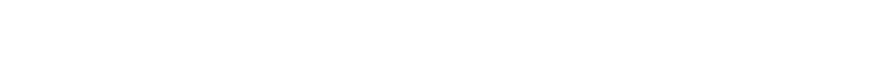

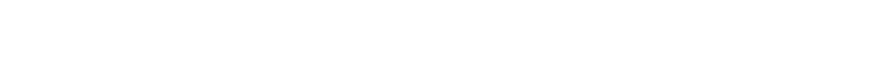

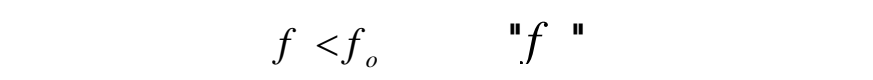

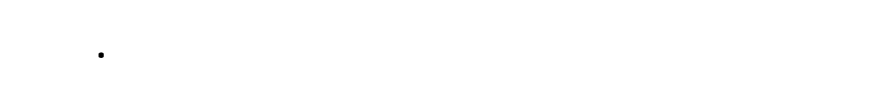

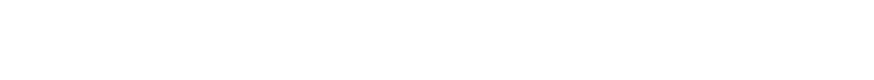

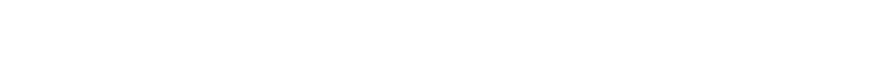


(C) Drs. I. Nasser and I. Abdel_Rahman

$2 / 25 / 2007$

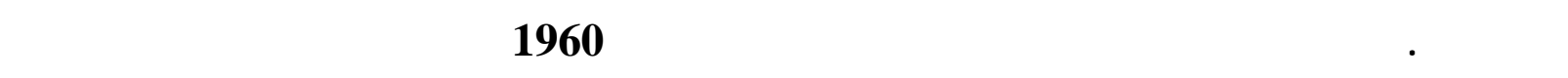

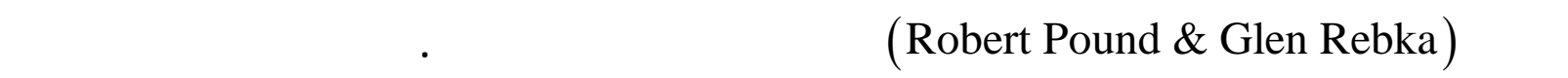

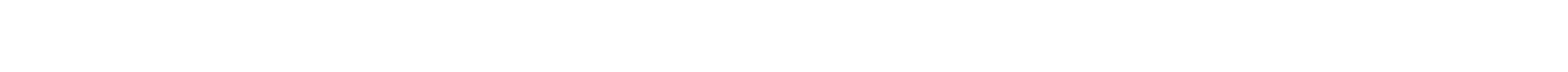
البيضiاء (White dwarfs).

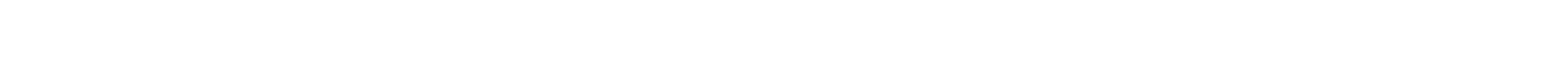

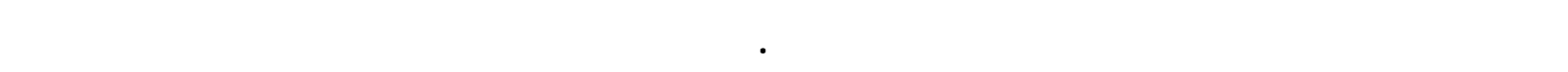
تنسبب من تمدد الزمن، ولا قملب ألي حركة من المصر أو الو المرلب.

الإثبلت الظلري للإزلة الحمراء: من ظلربة هيزنبرج الازدولجية لللالة والمالة، نجد أل علافة

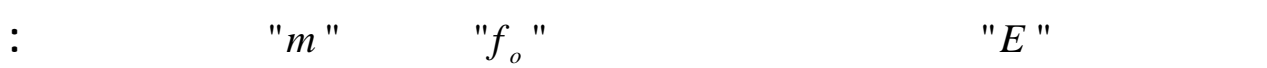
$E=m c^{2}=h f_{0}$

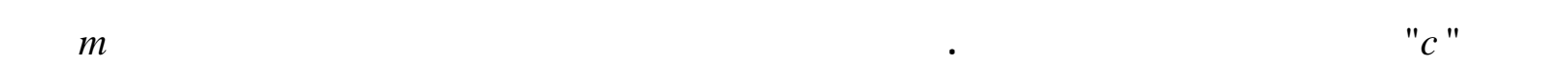

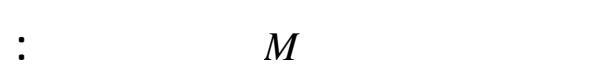

$$
U=-G \frac{M m}{r}=-G \frac{M h}{r c^{2}} f_{o}
$$

حيث هو شلبت الجافب. والآن عندما هروب الفوتهن من مجل الجانبيةسوف يكنب تردد مختلف

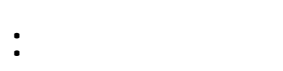

$$
h f=h f_{o}\left[1-G \frac{M}{r c^{2}}\right] \Rightarrow \frac{f-f_{o}}{f_{o}}=\frac{\Delta f}{f_{o}}=-G \frac{M}{r c^{2}}
$$

وحيث لن الإزالة بلتجاه القلالل من التردد فإنها تسع إزلهة الجانبية الحمراء أو الإزالة الحمراء

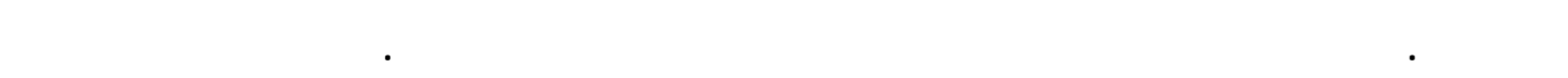

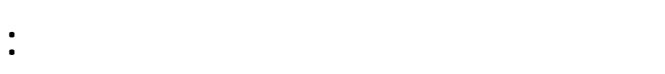

$$
h f=h f_{o}\left[1+G \frac{M}{r c^{2}}\right] \Rightarrow \frac{f-f_{o}}{f_{o}}=\frac{\Delta f}{f_{o}}=+G \frac{M}{r c^{2}}
$$

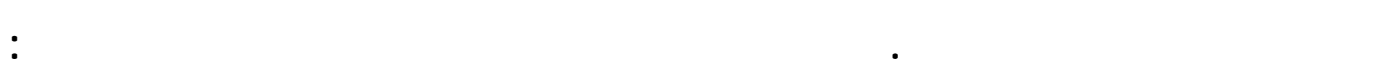

$$
f=f_{o}\left[1 \pm G \frac{M}{r c^{2}}\right]
$$


حيث أن الإشارة اللسالبة ( -) للضوء الهاربمن مجل جانبية النجم، ولإثارة الموجبة (+) للضوء السلافا في مجل جانبية النهم.

تهليقات:

3 - تنبلت ظلربة النسبية العامة بلن الكهن يتمدد إلى ما لا نهالية، أو ينكمش. ولم يسقاع آيشتنلين

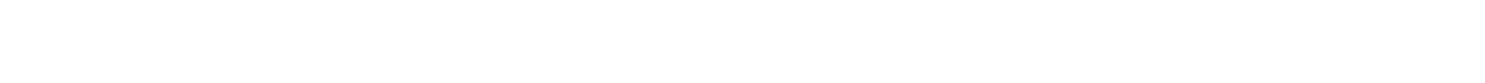
"Cosmological constant"

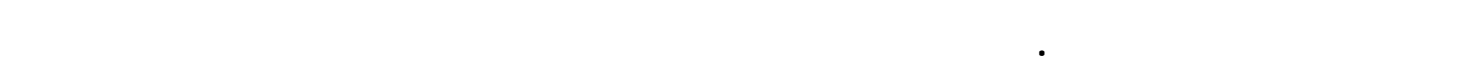

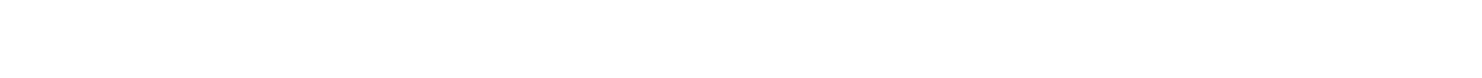

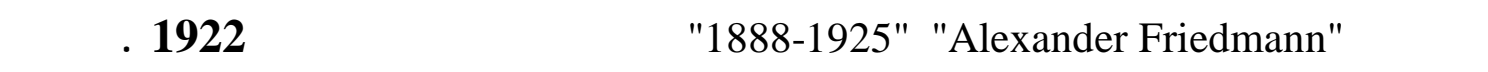

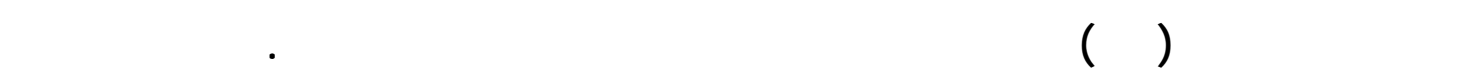
الثلاثة من علة الصفر. وبتنم النمونجل 1، 2 بأنهما يتمددل إلىملالنهالية. ألما النموذج رقم

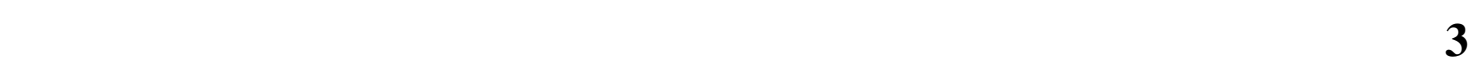

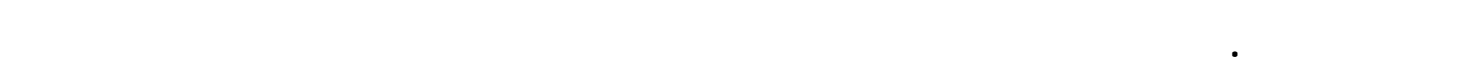

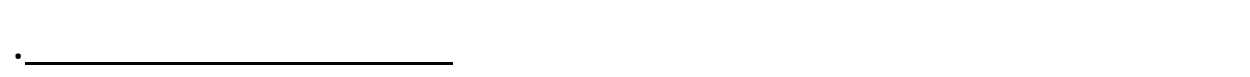
تمدد لم إبكماثك:

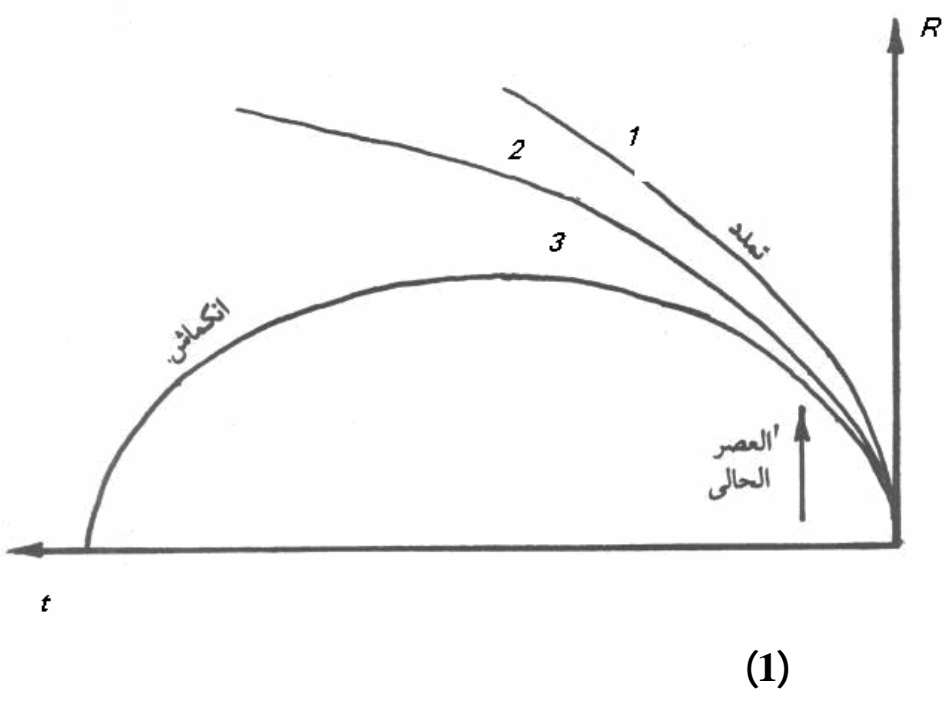


(C) Drs. I. Nasser and I. Abdel_Rahman

$2 / 25 / 2007$
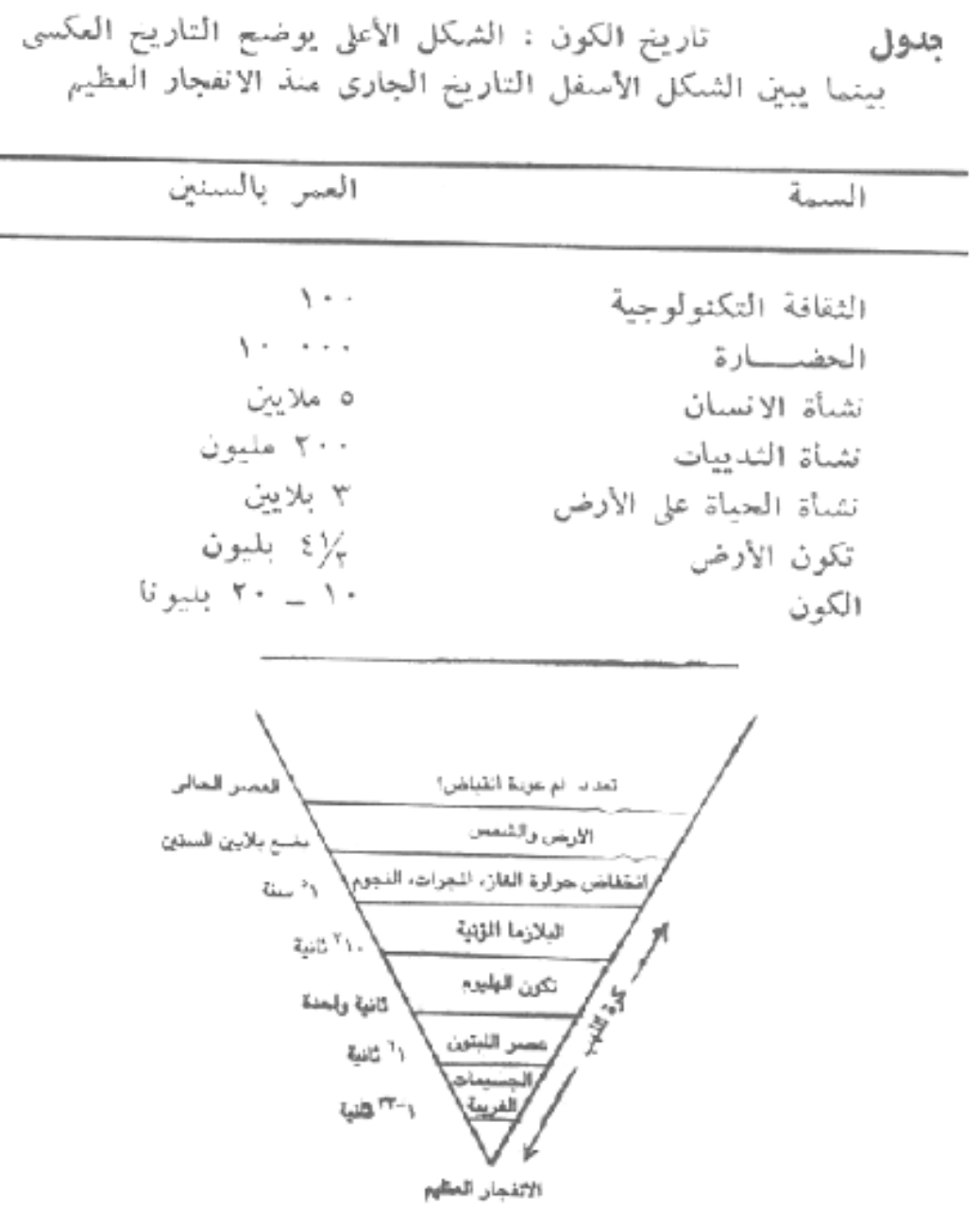

الانفجار العظيم 


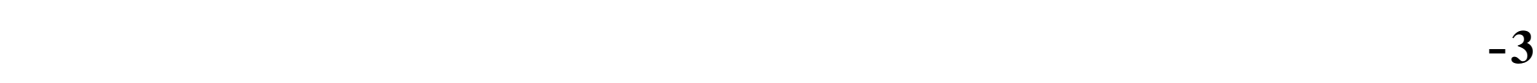

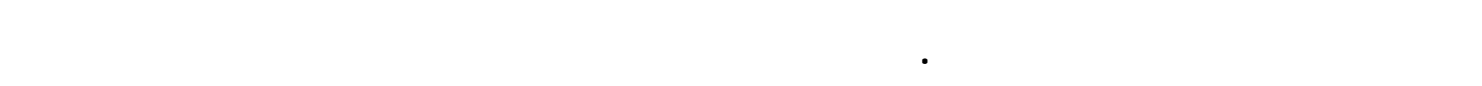

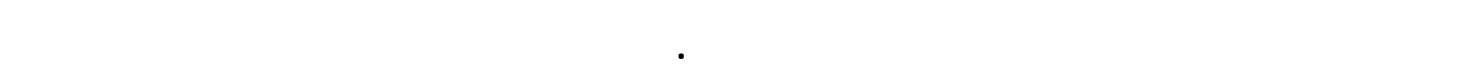

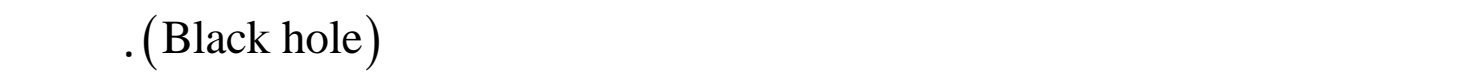

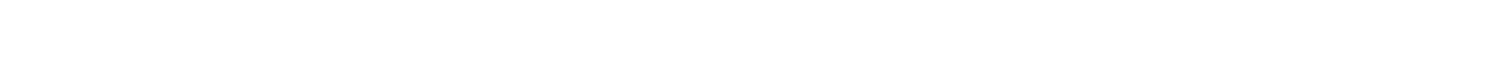

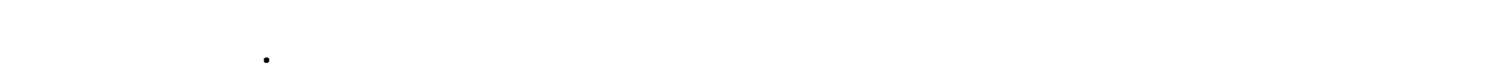

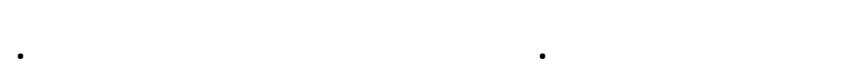
قب ألمود
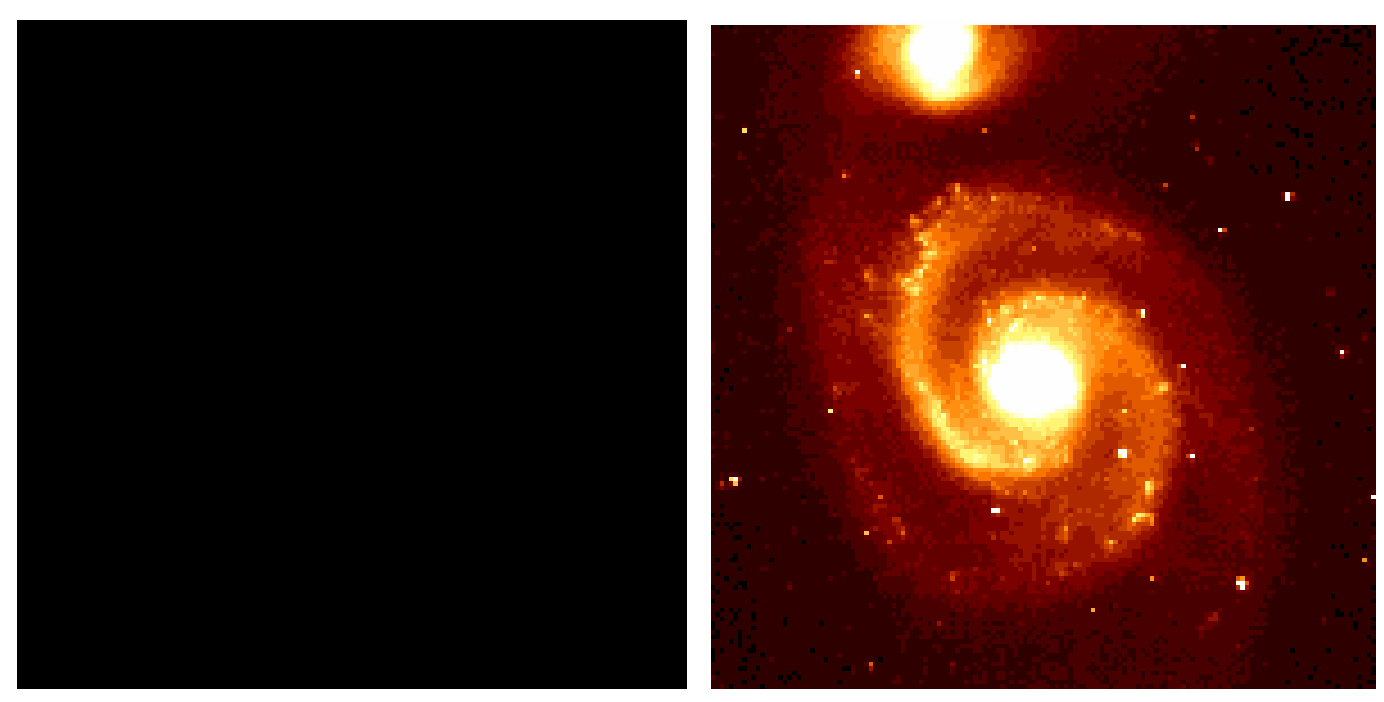
(C) Drs. I. Nasser and I. Abdel_Rahman

2/25/2007

قابقلت أخرى

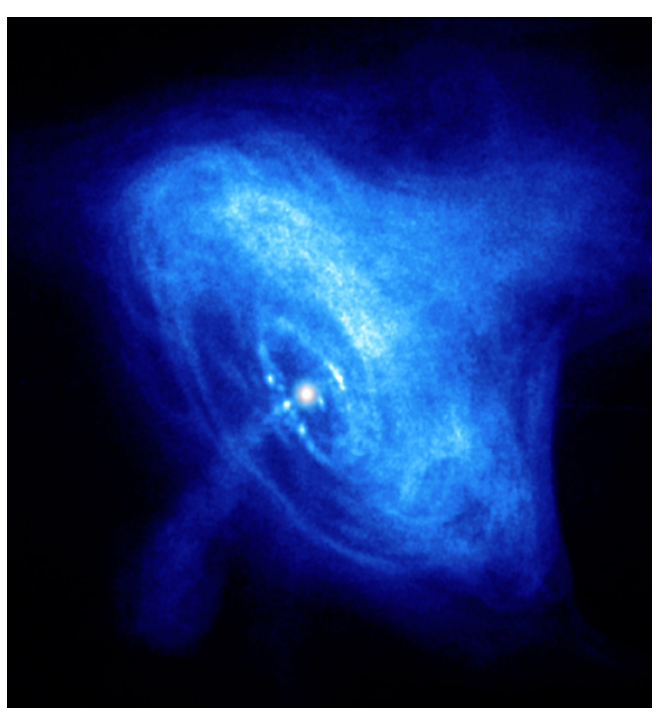

النجم النيتروف (Neutron star) نهم وطل إلي مرحلة الشيخوخة. يتكهن كلية ف الغالبمن

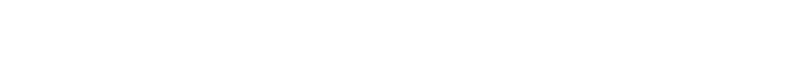
وكثلانه مرنفمة جداً.

الفزم الأبيض (White dwarf )

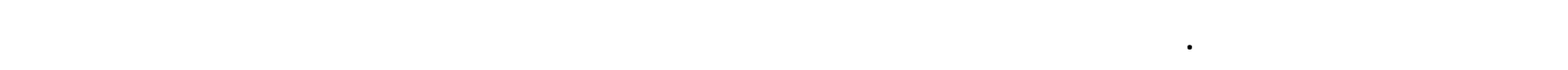

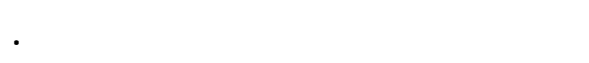
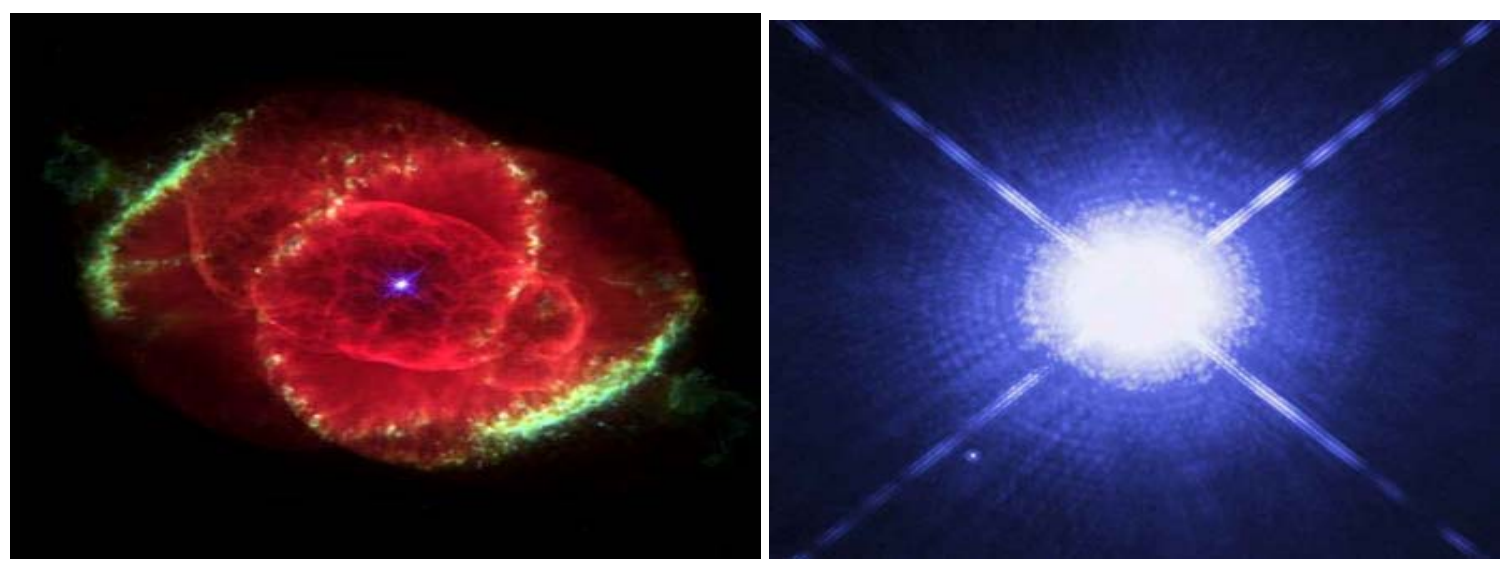
(C) Drs. I. Nasser and I. Abdel_Rahman $2 / 25 / 2007$

للمفر الكوف عبر الزملن
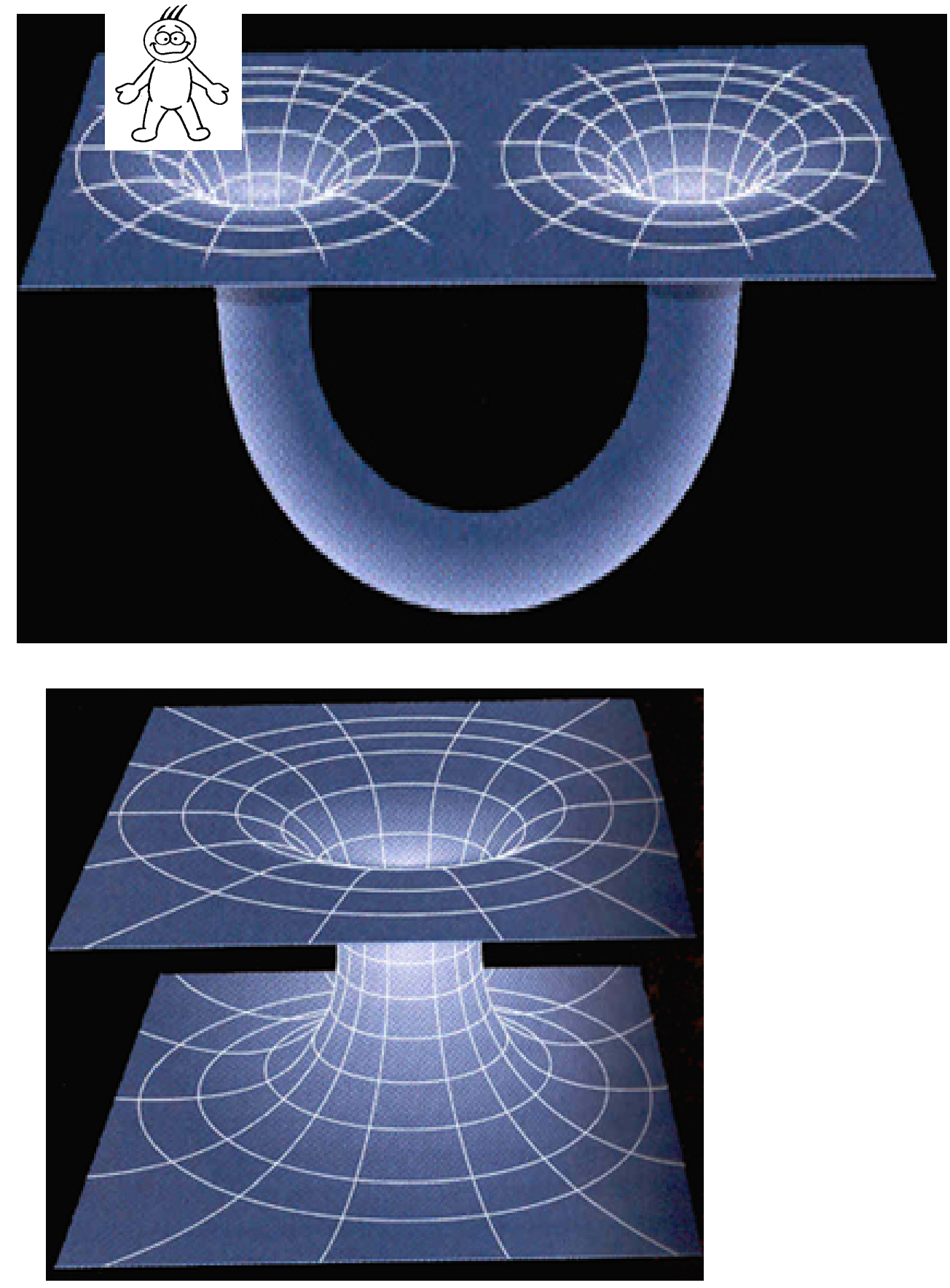